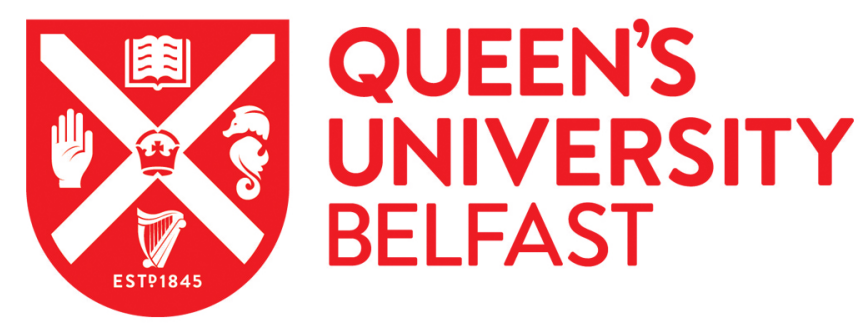

\title{
Inflammatory response following in vitro exposure to methylmercury with and without n-3 long chain polyunsaturated fatty acids in peripheral blood mononuclear cells from systemic lupus erythematosus patients compared to healthy controls
}

Crowe, W., Allsopp, P., Nyland, J. F., Magee, P. J., Strain, J. J., Doherty, L. C., Watson, G. E., Ball, E., Riddell, C., Armstrong, D. J., Penta, K., Todd, J. J., Spence, T., \& McSorley, E. M. (2018). Inflammatory response following in vitro exposure to methylmercury with and without n-3 long chain polyunsaturated fatty acids in peripheral blood mononuclear cells from systemic lupus erythematosus patients compared to healthy controls. Toxicology in Vitro, 52, 272-278. https://doi.org/10.1016/j.tiv.2018.05.008

Published in:

Toxicology in Vitro

Document Version:

Peer reviewed version

Queen's University Belfast - Research Portal:

Link to publication record in Queen's University Belfast Research Portal

\author{
Publisher rights \\ (C) 2018 Elsevier Ltd. \\ This manuscript is distributed under a Creative Commons Attribution-NonCommercial-NoDerivs License \\ (https://creativecommons.org/licenses/by-nc-nd/4.0/), which permits distribution and reproduction for non-commercial purposes, provided the \\ author and source are cited.
}

\section{General rights}

Copyright for the publications made accessible via the Queen's University Belfast Research Portal is retained by the author(s) and / or other copyright owners and it is a condition of accessing these publications that users recognise and abide by the legal requirements associated with these rights.

\section{Take down policy}

The Research Portal is Queen's institutional repository that provides access to Queen's research output. Every effort has been made to ensure that content in the Research Portal does not infringe any person's rights, or applicable UK laws. If you discover content in the

Research Portal that you believe breaches copyright or violates any law, please contact openaccess@qub.ac.uk. 
Inflammatory response following in vitro exposure to methylmercury with and without n-3 long chain polyunsaturated fatty acids in systemic lupus erythematosus patients compared to healthy controls.

William Crowe $^{1}$, Philip J. Allsopp ${ }^{1}$, Jennifer F. Nyland ${ }^{2,3}$, Pamela J. Magee ${ }^{1}$, JJ Strain ${ }^{1}$, Gene E. Watson ${ }^{4}$, Elisabeth Ball ${ }^{5}$, Claire Riddell ${ }^{5}$, David J. Armstrong ${ }^{6}$, Kayla Penta ${ }^{2}$, Joshua J. Todd $^{1}$, Toni Spence ${ }^{1}$, Emeir M. McSorley ${ }^{1}$

${ }^{1}$ Northern Ireland Centre for Food \& Health (NICHE), University of Ulster, Coleraine, BT52 1SA, Northern Ireland.

${ }^{2}$ University of South Carolina School of Medicine, Department of Pathology, Microbiology \& Immunology, 6439 Garner’s Ferry Rd., Building 1, Columbia, SC 29208, United States.

${ }^{3}$ Salisbury University, Department of Biological Sciences, 1101 Camden Ave, Salisbury, MD 21801, United States

${ }^{4}$ Eastman Institute for Oral Health and Department of Environmental Medicine, University of Rochester School of Medicine and Dentistry, Rochester, NY 14642, United States ${ }^{5}$ Department of Rheumatology, Musgrave Park Hospital, Stockman's Lane, Belfast, BT9 7JB, Northern Ireland.

${ }^{6}$ Department of Rheumatology, Altnagelvin Area Hospital, Glenshane Road, Londonderry BT47 6SB, Northern Ireland.

Correspondence to: Dr Emeir McSorley, Northern Ireland Centre for Food \& Health (NICHE), University of Ulster, Coleraine, BT52 1SA, Northern Ireland.

Email: em.mcsorley@ulster.ac.uk

Running title: Methylmercury and inflammation 


\section{Abstract}

The heavy metal methylmercury $(\mathrm{MeHg})$ is proposed as an environmental stimulus in the pathogenesis of systemic lupus erythematosus (SLE). Humans are primarily exposed to $\mathrm{MeHg}$ through fish consumption. Fish are the main dietary source of n-3 long chain polyunsaturated fatty acids (n-3 LCPUFA), which have been shown to be anti-inflammatory and beneficial to health. This ex-vivo study investigated the inflammatory response of isolated peripheral blood mononuclear cells (PBMCs) from SLE patients and healthy controls when exposed to $\mathrm{MeHgCl}_{2}$. The difference in inflammatory response between SLE patients and healthy controls following co-exposure of cells to $\mathrm{MeHgCl}_{2}$ and n-3 LCPUFA was also investigated. Separately, in the SLE and in the control group, the effect of co-exposure to $\mathrm{MeHgCl}_{2}$ and $\mathrm{n}-3$ LCPUFA on cytokine concentrations compared with the effect of $\mathrm{MeHgCl}_{2}$ alone was investigated. A total of 12 SLE patients and 12 age and sex matched controls were recruited. PBMCs were isolated and exposed to $200 \mathrm{nM}$ of $\mathrm{MeHgCl}_{2}$ in the presence of lipopolysaccharide (LPS) for $24 \mathrm{hr}$ with or without co-exposure of the n-3 LCPUFA eicosapentaenoic acid (EPA) and docosahexaenoic acid (DHA) at a concentration of $100 \mu \mathrm{M}$. Supernatants were analysed for the inflammatory markers IL-1 $\beta$, IL-2, IL-4, IL-6, IL-8, IL-10, IL-12p70, IL-13 and TNF$\alpha$. Following exposure to $\mathrm{MeHgCl}_{2}$ and LPS, the mean TNF- $\alpha$ concentrations in the supernatants from SLE patients $(2226.01 \pm 348.98 \mathrm{pg} / \mathrm{ml})$ was significantly higher than those from matched controls $(701.40 \pm 680.65 \mathrm{pg} / \mathrm{ml})(\mathrm{P}=0.008)$. Co-exposure of cells with $\mathrm{MeHgCl}_{2}$, EPA and LPS resulted in a significantly higher concentration of IL-8 in supernatants from SLE patients $(2137.83 \pm 1559.01 \mathrm{pg} / \mathrm{ml})$ compared to that of healthy controls $(879.26 \pm 979.49$ $\mathrm{pg} / \mathrm{ml}) \quad(\mathrm{P}=0.030)$. Cells from SLE patients co-exposed to $\mathrm{MeHgCl}_{2}, \mathrm{n}-3$ LCPUFA and LPS elicited significantly lower concentrations of IL-1 $\beta$, IL-2, IL-8 and TNF- $\alpha$ compared with SLE cells exposed to $\mathrm{MeHgCl}_{2}$ and LPS. Cells from healthy controls co-exposed to $\mathrm{MeHgCl}_{2}, \mathrm{n}-3$ LCPUFA and LPS elicited significantly lower concentrations of IL-1 $\beta$, IL-2, IL-4, IL-6 and 
TNF- $\alpha$ compared with healthy cells exposed to $\mathrm{MeHgCl}_{2}$ and LPS. This study suggests that SLE patients are hyper-responsive to $\mathrm{MeHgCl}_{2}$ exposure in the presence of LPS and supports a role for n-3 LCPUFA in ameliorating inflammation in SLE patients.

Keywords: methylmercury, EPA, DHA, lupus, inflammation 


\section{Introduction}

Systemic lupus erythematosus (SLE) is a prototypic chronic autoimmune disease with a variable presentation characterised by a loss of tolerance to self-antigen, autoantibody production and a dysregulated inflammatory response ${ }^{1}$. A number of environmental factors are implicated in the pathogenesis of $\mathrm{SLE}^{2}$ including that of mercury $(\mathrm{Hg})$ exposure ${ }^{3}$. Humans are exposed to $\mathrm{Hg}$ in several forms including, elemental mercury $\left(\mathrm{Hg}^{0}\right)$ through dental amalgams, ethyl mercury $(\mathrm{EtHg})$ through some vaccinations and methylmercury ( $\mathrm{MeHg}$ ) through contaminated fish consumption. $\mathrm{MeHg}$ is an organic compound found in aquatic environments following the methylation of inorganic $\mathrm{Hg}(\mathrm{iHg}) . \mathrm{MeHg}$ accumulates in fish, with higher amounts being found in large predatory species such as shark and swordfish $^{4,5}$. MeHg exposure from fish consumption is of public health concern because once consumed $\mathrm{MeHg}$ is distributed widely throughout the human body and can cross the placental barrier, and the blood brain barrier ${ }^{6}$. The developing brain is particularly vulnerable to neurotoxic effects of $\mathrm{MeHg}^{7}$. Conversely, fish is a valuable source of protein contributing to $17 \%$ of the world's animal protein intake ${ }^{8}$. Fish also contain n-3 long chain polyunsaturated fatty acids (n-3 LCPUFA) which have been shown to have numerous beneficial effects on health 9

In vitro research has reported that $\mathrm{MeHg}$ exposure results in an increase in interleukin (IL)-1 $\beta$ concentrations from human peripheral blood mononuclear cells (PBMCs) ${ }^{10}$ whilst $\mathrm{MeHg}$ exposure in animal studies has been shown to increase concentrations of interferon (IFN)- $\gamma^{11}$. Furthermore, $\mathrm{MeHg}$ exposure resulted in the development of a systemic autoimmunity in murine models that are genetically predisposed to metal-induced autoimmunity ${ }^{12-14}$. Murine MeHg-induced autoimmunity appears to be less severe than murine iHg-induced autoimmunity in that no immune complexes (IC) are deposited in organs of $\mathrm{MeHg}$ exposed mice $^{15}$. A limited number of human studies have investigated the effects of $\mathrm{MeHg}$ on 
autoimmunity. Two observational studies have reported an association between $\mathrm{MeHg}$ exposure and the production of antinuclear autoantibodies, suggesting that long term low dose exposure to $\mathrm{MeHg}$ may increase the risk of autoimmunity in healthy individuals ${ }^{16,17}$.

Fish contain several health promoting nutrients, most notably the n-3 LCPUFA eicosapentaenoic acid (EPA) and docosahexaenoic acid (DHA) that have been shown to have potent anti-inflammatory effects. ${ }^{18}$ Several in vitro studies have shown that EPA and DHA can decrease the production of the pro-inflammatory cytokines IL-1, IL-6 and tumour necrosis factor (TNF)- $\alpha$ from human (endothelial, monocyte) and murine (macrophage) cell lines. ${ }^{19-24}$ Furthermore, fish oil supplementation in mice that are genetically susceptible to autoimmunity has been shown to attenuate the secretion of pro-inflammatory cytokines, ${ }^{25,26}$ delay the onset of autoimmunity, ${ }^{27,28}$ and in some cases ameliorate autoimmunity entirely. ${ }^{29,30}$ The results from human studies concur with those reported from in vitro and animal research in that supplementation of autoimmune patients with EPA and DHA has been shown to decrease pro-inflammatory cytokines, ${ }^{31,32}$ and improve health outcomes. ${ }^{33-36}$

Although fish are rich in EPA and DHA which have been shown to be beneficial to SLE patients, fish are also a source of $\mathrm{MeHg}$ which has been suggested to be an environmental stimulus in the pathogenesis of SLE. This ex-vivo study will investigate the inflammatory response of isolated PBMC from SLE patients and healthy controls when exposed to $\mathrm{MeHgCl}_{2}$ and LPS. The difference in inflammatory response between SLE and healthy control PBMCs following ex-vivo co-exposure to $\mathrm{MeHgCl}_{2}$, LPS and n-3 LCPUFA will be compared. Separately, in the SLE and in the control group, the effect of co-exposure to $\mathrm{MeHgCl}_{2}$ and n-3 LCPUFA on cytokine concentrations compared with the effect of $\mathrm{MeHgCl}_{2}$ alone will be investigated. 


\section{Materials and Methods}

\section{Study population}

Ethical approval (15/NI/0062) was granted by the Office of Research Ethics Committees Northern Ireland (ORECNI). PBMCs were isolated from 12 female SLE patients and 12 age (+/-5 years) and sex matched healthy controls. Participants suffering from SLE, who previously participated in research and consented, were contacted and recruited to take part in the current study. Each SLE participant met at least 4 of the 11 American College of Rheumatology diagnostic criteria ${ }^{37}$ and were previously verified by a consultant rheumatologist in $2011{ }^{38}$ SLE patients were excluded if they self-reported that they were currently taking steroids, non-steroidal anti-inflammatory drugs or supplementing with fish oils. Healthy controls were excluded if they had a history of autoimmune disease, were currently suffering from an acute illness or were currently taking non-steroidal antiinflammatory drugs, or supplementing with fish oils.

\section{Materials}

All chemicals were purchased from Sigma-Aldrich unless otherwise stated. Phosphate buffered saline (PBS) was obtained from Analab (Lisburn, UK). Roswell Park Memorial Institute medium (RPMI) 1640, penicillin streptomycin, L-glutamine and heat inactivated foetal bovine serum (hi-FBS) were purchased from Invitrogen (Paisley, UK). $\mathrm{MeHgCl}_{2}$, the commonly used analog of $\mathrm{MeHg}$, was reconstituted in PBS at a stock concentration of $3 \mathrm{mM}$ and sterile filtered before being diluted to a working concentration of $200 \mathrm{nM}$. EPA and DHA were each dissolved in ethanol at a concentration of $10 \mathrm{mM}$ and stored at $-80^{\circ} \mathrm{C}$. EPA and DHA were diluted in RPMI to a final concentration of $100 \mu \mathrm{M}$ each with $1 \%$ hi-FBS, $2 \% \mathrm{w} / \mathrm{v}$ 
bovine serum albumin and $1 \%$ ethanol. The EPA and DHA mixtures were vortexed for 10 minutes and incubated for $2 \mathrm{~h}$ at $37^{\circ} \mathrm{C}$ prior to addition with cell culture. LPS was prepared in PBS at a stock concentration of $1 \mathrm{~g} / \mathrm{ml}$ and frozen at $-80^{\circ} \mathrm{C}$. All experiments used LPS aliquots from the same batch. All lab ware was endotoxin free (less than $0.5 \mathrm{EU}$ ).

Peripheral blood mononuclear cell isolation

A fasting blood sample was obtained from participants by venepuncture from the median antebrachial vein into $3 \mathrm{x} 9 \mathrm{ml}$ sodium heparin tubes for isolation of PBMCs. Blood samples were diluted 2:1 (v/v) with RPMI 1640 media and added to a LeucoSep ${ }^{\text {TM }}$ tube (Aquilant Scientific, Belfast, UK) and centrifuged at $1000 \mathrm{~g}$ for 10 minutes. The buffy layer containing PBMCs was isolated and subsequently washed using RPMI 1640.

Cell culture and exposure

PBMCs were maintained in culture at a density of $1 \times 10^{6}$ cells $/ \mathrm{ml}$ in RPMI 1640 with $25 \mathrm{mM}$ 4-(2-hydroxyethyl)-1-piperazineethanesulfonic acid (HEPEs) supplemented with \% 1glutamine, $5 \%$ penicillin streptomycin, and 10\% hi-FBS along with $100 \mu \mathrm{M}$ EPA, $100 \mu \mathrm{M}$ DHA or vehicle control at $37^{\circ} \mathrm{C}$ and $5 \% \mathrm{CO}_{2}$ for 24 hours. Cells were then exposed to $200 \mathrm{nM}$ $\mathrm{MeHgCl}_{2}$ and $50 \mathrm{ng} / \mathrm{ml}$ LPS or vehicle control for a further period of 24 hours at $37^{\circ} \mathrm{C}$ (Figure 1). Following centrifugation, supernatants were immediately stored at $-80^{\circ} \mathrm{C}$ until analysis. 
Previous studies have reported that $200 \mathrm{nM}$ of $\mathrm{MeHgCl}_{2}$ is not cytotoxic to $\mathrm{PBMCs}^{10,39}$. In order to confirm that the change in inflammatory markers were not owing to non-specific cytotoxicity a $200 \mu 1$ aliquot of cells from each participant post exposure was seeded in a 96 well plate. A $15 \mu 1$ aliquot of 3-(4, 5-dimethylthiazol-2-yl)-2, 5-diphenyltetrazolium bromide (MTT) $(500 \mu \mathrm{g} / \mathrm{ml})$ was added to each well and incubated for 4 hours at $37^{\circ} \mathrm{C}$ followed by the addition of $100 \mu 1$ solubilizing solution (10\% triton $\mathrm{X}$ in acidic isopropanol-2) and a further incubation period of 2 hours at $37^{\circ} \mathrm{C}$. Absorbance values were measured on a VersaMax plate reader (Molecular devices, Sunnyvale CA) at a wave length of $570 \mathrm{~nm}$ and $630 \mathrm{~nm}$ and expressed as optical density (OD). This assay is based on the principle that viable cells metabolise tetrazolium salt to a purple formazan as previously described. ${ }^{40}$

\section{Cytokine analysis}

Cytokine secretion by PBMCs was measured by the electro chemiluminescence-based Meso Scale Discovery (MSD) immunoassay (Meso Scale Discovery, Gaithersburg, MD, USA). MSD plates were analyzed on the MS2400 imager MSD. IL-1 $\beta$, IL-2, IL-4, IL-6, IL-8, IL-10, IL-12p70, IL-13 and TNF- $\alpha$ concentrations were calculated using the manufacturer's software and results are presented as mean $( \pm \mathrm{SD})$ in $\mathrm{pg} / \mathrm{ml}$. The lower limits of detection for each cytokine were: IL-1 $\beta$, IL-8 and TNF- $\alpha ; 0.4$ pg/ml, IL-2; 0.09 pg/ml, IL-4; 0.02, IL-6; $0.06 \mathrm{pg} / \mathrm{ml}, \mathrm{IL}-10 ; 0.03 \mathrm{pg} / \mathrm{ml}, \mathrm{IL}-12 \mathrm{p} 70 ; 0.11 \mathrm{pg} / \mathrm{ml}, \mathrm{IL}-13 ; 0.24 \mathrm{pg} / \mathrm{ml}$. The CVs for each cytokine were IL-1 $\beta=4.4 \%$, IL-2 = 7.1\%, IL-4 =18\%, IL-6 =7.2\%, IL-8 = 5.8\%, IL-10 = $8.2 \%$, IL- $12 \mathrm{p} 70=11.7 \%$, IL- $13=7.8 \%$ and TNF- $\alpha=5.2 \%$.

\section{Statistical analysis}


Statistical comparisons were completed using IBM® ${ }^{\circledR}$ SPSS ${ }^{\circledR}$ Statistics v22. Skewed data were transformed for analysis using the Shapiro-Wilk test. Results are displayed using the original mean $( \pm \mathrm{SD})$. Mean OD values post MTT were converted to percentage change relative to cells exposed to media alone. The mean cell viability from all 24 participants following each condition was compared with the mean cell viability from media exposed cells using analysis of variance (ANOVA). The differences in cytokine concentrations between SLE participants and healthy controls exposed to $\mathrm{MeHgCl}_{2}$ and LPS was assessed using analysis of covariance (ANCOVA), with cytokine concentrations from cells exposed to LPS alone as a covariate. The difference in cytokine concentrations between SLE participants and healthy controls exposed to $\mathrm{MeHgCl}_{2}$ and EPA or DHA was assessed using ANCOVA with cytokine concentrations from cells exposed to LPS and $\mathrm{MeHgCl}_{2}$ as a covariate. Further analysis compared the within group (SLE and healthy controls separately) effect of coexposure to $\mathrm{MeHgCl}_{2}$, EPA and DHA on cytokine concentrations compared with the effect of $\mathrm{MeHgCl}_{2}$ alone using an independent $\mathrm{T}$ test.

\section{Results}

Study population

All SLE patients recruited to this study were female, the mean age $( \pm \mathrm{SD})$ of the SLE cohort was $42.08( \pm 13.34)$ years. The mean age $( \pm \mathrm{SD})$ of the matched controls was $41.89( \pm 14.12)$ years.

\section{Cell viability}

The average absorbance of the negative control was $0.2 \mathrm{OD}$. The MTT assay confirmed that cells exposed to LPS, $\mathrm{MeHgCl}_{2}, \mathrm{MeHgCl}_{2}$ and LPS, $\mathrm{MeHgCl}_{2}$ LPS and EPA, $\mathrm{MeHgCl}_{2} \mathrm{LPS}$ and DHA did not cause a significant decrease in cell viability in comparison to cells exposed 
to media alone. The mean change in cell viability relative to the media control was shown to be $\mathrm{LPS}=-11 \%, \mathrm{MeHgCl}_{2}=-5 \%, \mathrm{MeHgCl}_{2}$ and LPS $=-8 \%, \mathrm{MeHgCl}_{2} \mathrm{LPS}$ and $\mathrm{EPA}=+7 \%$, $\mathrm{MeHgCl}_{2}$ LPS and DHA $=+3 \%$.

$\mathrm{MeHgCl}_{2}$ exposure: comparing inflammatory response between SLE and controls Similar to Gardner et al. (2010), ${ }^{39}$ no differences were observed in cytokine concentrations between cells exposed to $\mathrm{MeHgCl}_{2}$ alone compared with cells treated with media (data not shown). Exposure of SLE patients' PBMCs to $\mathrm{MeHgCl}_{2}$ and LPS resulted in a significantly higher concentration of TNF- $\alpha(\mathrm{P}=0.008)$ when compared to cytokine concentrations from healthy control PBMCs also exposed to $\mathrm{MeHgCl}_{2}$ and LPS (Table 1).

$\mathrm{MeHgCl}_{2}$ and LCPUFA exposure: comparing inflammatory response between SLE and controls

PBMCs from SLE patients secreted significantly higher concentrations of IL-8 following exposure to $\mathrm{MeHgCl}_{2}$, LPS and EPA compared to PBMCs from healthy controls under the same conditions $(\mathrm{P}=0.030)$ (Table 2$)$.

There was no difference in cytokine concentration between SLE patients and healthy controls following exposure to $\mathrm{MeHgCl}_{2}$, LPS and DHA (Table 3).

Inflammatory response of SLE patients following $\mathrm{MeHgCl}_{2}$ and LCPUFA exposure PBMCs from SLE patients exposed to $\mathrm{MeHgCl}_{2}$, LPS and EPA had significantly lower mean concentrations of IL-1 $\beta(\mathrm{P}=0.001), \mathrm{IL}-8(\mathrm{P}=0.007)$ and TNF- $\alpha(\mathrm{P}=0.048)$ compared with PBMCS from SLE patients exposed to $\mathrm{MeHgCl}_{2}$ and LPS in the absence of EPA. PBMCs from SLE patients exposed to $\mathrm{MeHgCl}_{2}$, LPS and DHA had significantly lower mean 
concentrations of IL-1 $\beta(\mathrm{P}=0.003), \mathrm{IL}-2(\mathrm{P}=0.003), \mathrm{IL}-8(\mathrm{P}=0.010)$ and TNF- $\alpha(\mathrm{P}=0.009)$ compared with PBMCs from SLE patients' cells exposed solely to $\mathrm{MeHgCl}_{2}$ and LPS.

\section{Inflammatory response of controls following $\mathrm{MeHgCl}_{2}$ and LCPUFA exposure}

PBMCs from healthy controls exposed to $\mathrm{MeHgCl}_{2}$, LPS and EPA had significantly lower mean concentrations of IL-1 $\beta(\mathrm{P}=0.002)$, IL-2 $(\mathrm{P}=0.015)$, IL-4 $(\mathrm{P}=<0.001)$, IL-6 $(\mathrm{P}=<0.001)$, and TNF- $\alpha(\mathrm{P}=0.002)$ compared with PBMCs from healthy controls exposed to $\mathrm{MeHgCl}_{2}$ and LPS in the absence of EPA. PBMCs from healthy controls co-exposed to $\mathrm{MeHgCl}_{2}$, LPS and DHA had significantly lower mean concentrations of IL-1 $\beta$ ( $\mathrm{P}=0.001)$, IL-2 ( $\mathrm{P}=0.015)$, IL-4 $(\mathrm{P}=<0.001)$, IL-6 $(\mathrm{P}=<0.001)$, and TNF- $\alpha(\mathrm{P}=0.002)$ compared with PBMCS from healthy controls exposed solely to $\mathrm{MeHgCl}_{2}$ and LPS.

\section{Discussion}

SLE patients appear to be more responsive to the inflammatory inducing effects of ex vivo MeHg exposure, as PBMCs from SLE patients elicited higher concentrations of TNF- $\alpha$ compared to those of the control group. Co-exposure to MeHg and n-3 PUFA resulted in a lower inflammatory response albeit PBMCs from SLE patients secreted higher concentrations of IL-8 following $\mathrm{MeHgCl}_{2}$, LPS and EPA exposure when compared with healthy controls under the same conditions. Overall, both EPA and DHA appear to mitigate the $\mathrm{MeHgCl}_{2}-$ induced inflammatory response, albeit the effect was weaker in SLE patients than in controls suggesting SLE patients may require higher concentrations of n-3 LCPUFA.

Cells from SLE patients secreted higher concentrations of TNF- $\alpha$ than healthy controls following ex vivo $\mathrm{MeHgCl}_{2}$ exposure in the presence of the adjuvant LPS. TNF- $\alpha$ is upregulated in lupus nephritis ${ }^{41}$ and is positively correlated with disease activity. ${ }^{42}$ Infliximab 
is a medication directed against TNF- $\alpha$ and its use has been shown to have a beneficial effect on joint tenderness and proteinuria in SLE patients with arthritis and nephritis. ${ }^{43,44}$ Therefore, the $\mathrm{MeHgCl}_{2}$-induced rise in TNF- $\alpha$ concentrations observed in this study could potentially be detrimental to health. However, we observed that co-exposure with both EPA and DHA ameliorated this significant increase in TNF- $\alpha$ and as MeHg is typically encountered in the presence of n-3 LCPUFA this suggests that n-3 LCPUFA outweigh any detrimental inflammatory effects of $\mathrm{MeHgCl}_{2}$. Similar findings have been reported when assessing the effects of fish consumption on child development. ${ }^{45-48}$

This study demonstrated that the anti-inflammatory effects of n-3 LCPUFA are more potent in PBMCs from healthy controls compared to SLE patients. SLE patients had significantly higher concentrations of IL-8 compared with healthy controls following $\mathrm{MeHgCl}_{2}$, LPS and EPA exposure. The role of IL-8 is critical to leukocyte infiltration which could lead to neutrophil-induced tissue damage in patients with SLE through enhanced secretion of neutrophil elastase, cathepsins and myeloperoxidase. ${ }^{49}$ Neutrophil elastase and cathepsins can breakdown renal tissue through the proteolysis of both collagen-IV and elastin ${ }^{49,50}$ whereas myeloperoxidase elicits deleterious effects through oxidative damage. ${ }^{51}$ Urinary concentrations of IL-8 are higher in SLE patients with glomerular diseases compared with healthy controls. ${ }^{52}$ It is plausible that SLE patients require a higher intake of n-3 PUFAs to achieve the same anti-inflammatory effects as in healthy controls.

EPA mitigated the MeHg-induced rise in IL-1 $\beta$, IL-8 and TNF- $\alpha$ in SLE patients and the MeHg-induced rise in IL-1 $\beta$, IL-2, IL-4, IL-6, and TNF- $\alpha$ in healthy controls. DHA mitigated the MeHg-induced rise in IL-1 $\beta$, IL-2, IL-8, and TNF- $\alpha$ in SLE patients and the MeHginduced rise in IL-1 $\beta$, IL-2, IL-4, IL-6, and TNF- $\alpha$ in healthy controls. 
Both EPA and DHA mitigate the $\mathrm{MeHgCl}_{2}$-induced rise in IL-2, IL-4, and IL-6 in healthy controls and only DHA mitigated the $\mathrm{MeHgCl}_{2}$-induced rise in IL-2 in SLE patients. These cytokines are involved in B cell differentiation and subsequently humoral immunity, which is dysregulated in SLE. ${ }^{53}$ The raised concentrations of IL-2, IL-4 and IL-6 in SLE could result in an enhanced production of Th2 cells, which could further perpetuate the production of autoantibodies. ${ }^{54}$ EPA and DHA significantly decreased IL-8 in SLE patients but not in healthy controls. IL-8 is secreted from macrophages, which are part of the innate immune system. It is possible that n-3 LCPUFA are unable to decrease cytokines regulated by humoral immune cells due to the dysregulation of humoral immunity in SLE. The mechanism responsible for the difference in response to EPA and DHA between SLE patients and healthy controls needs to be investigated.

The n-3 and n-6 LCPUFA are precursors to leukotrienes, prostaglandins and thromboxanes. Arachidonic acid, a potent n-6 LCPUFA is a substrate in the production of leukotrienes LTC4 and LTD4 through lipoxygenase (LOX) or prostaglandins (PGD2, PGE2, PGF2) and thromboxane (TXA2) through cyclooxygenase (COX). These leukotrienes, prostaglandins and thromboxanes lead to an increase in pro-inflammatory cytokines. ${ }^{55}$ EPA and DHA are also substrates for eicosanoids producing less pro-inflammatory derivatives such as PG3, LTB3 and LTC5. Therefore, when n-3 LCPUFA are available as substrates there is an inhibition of n-6 LCPUFA produced eicosanoids in favour of n-3 derived eicosanoids and a less pronounced pro-inflammatory effect results. ${ }^{56} \mathrm{~A}$ further mechanism that could be acting in conjunction with the above is the activation of nuclear transcription factors peroxisome proliferator-activated receptors (PPARs). EPA and DHA are agonists for the PPAR- $\gamma /$ RXR complex which upon activation will subsequently translocate to the nucleus to alter gene expression. Activation of the PPAR- $\gamma / \mathrm{RXR}$ complex has been shown to prevent the 
translocation of $\mathrm{NF} \kappa \mathrm{B}$ to the nucleus which results in decreased transcription of its proinflammatory targets including TNF- $\alpha$, IL-1, IL-6 and IL- $8 .{ }^{57}$ The decrease in production of pro-inflammatory cytokine elicited by EPA and DHA has been suggested to contribute to the clinical benefits noted following n-3 LCPUFA supplementation. Several human intervention studies have reported a decrease in disease activity in SLE patients following n-3 LCPUFA supplementation, ${ }^{33-36}$ albeit the molecular mechanism responsible for this effect in human studies remains to be elucidated.

The n-6 LCPUFA were not present in any of the experimental conditions in this study and therefore the n-3 LCPUFA effect may have been heightened and it is important to consider this when interpreting these results. A strength of this study is that the dosage used of EPA and DHA translates to a blood concentration of $0.1 \mathrm{mmol} / 1$, which is achievable in the general population. ${ }^{58}$ Nevertheless, the true effect of n-3 LCPUFAs on mitigating the inflammatory effect of $\mathrm{MeHg}$ exposure should be tested in individuals, with and without SLE, who regularly consume fish. Furthermore, the inclusion of patients who are suffering from a disease flare could further aid in the understanding of how environmental factors preclude and perpetuate disease severity. This study did not statistically control for medication intake such as hydroxychloroquine and methotrexate which have been shown to effect cytokine secretion from PBMC. ${ }^{59,60}$ The use of $\mathrm{MeHgCl}_{2}$ rather than $\mathrm{MeHg}$ in this study means it is not truly presentative of $\mathrm{MeHg}$ consumed through fish. $\mathrm{MeHg}$ when ingested is conjugated with L-cysteine and forms a molecule similar to L-methionine. Cells uptake $\mathrm{MeHgCl}_{2}$ through diffusion whilst MeHg-cysteine is taken up via a carrier. ${ }^{61}$

Conclusion 
This research investigated the difference in inflammatory response of SLE patients to that of healthy controls following ex vivo $\mathrm{MeHgCl}_{2}$ and LPS exposure with or without pre-treatment with n-3 LCPUFA. The ex vivo exposure to $\mathrm{MeHgCl}_{2}$ and LPS promotes inflammation in SLE patients and healthy controls; however, SLE patients have a stronger pro-inflammatory effect. Both EPA and DHA decreased $\mathrm{MeHg} \mathrm{Cl}_{2}$ induced inflammation albeit EPA and DHA appear to be less effective in SLE patients compared with healthy controls. Taken together the results from this study suggests that inflammation promoting effects from low dose $\mathrm{MeHgCl}_{2}$ exposure can be mitigated by n-3 LCPUFA. Therefore, the benefit of consuming a diet of fish rich in n-3 LCPUFA for SLE patients appears to outweigh any potential inflammatory effect of $\mathrm{MeHg}$. Further research is required to investigate the effect of $\mathrm{MeHg}$ exposure in individuals with SLE to investigate the risk/benefits of fish consumption in SLE.

\section{Conflict of interest}

The authors declare that there are not conflicts of interest

\section{Acknowledgements and Funding}

This research was supported financially by the Northern Ireland Department of Employment and Learning (DEL). We wish to acknowledge Ms. Cècile Bigand of Université Nice Sophia Antipolis, for providing help with laboratory analysis. 


\section{References}

1. Mok CC, Lau CS. Pathogenesis of systemic lupus erythematosus. Journal of clinical pathology 2003; 56: 481-490.

2. Kamen DL. Environmental influences on systemic lupus erythematosus expression. Rheumatic Disease Clinics of North America 2014; 40: 401-412.

3. Pollard KM, Pearson DL, Hultman P, Deane TN, Lindh U, Kono DH. Xenobiotic acceleration of idiopathic systemic autoimmunity in lupus-prone bxsb mice. Environmental Health Perspectives 2001; 109: 27.

4. Dietz R, Rigét FF, Born EW. An assessment of selenium to mercury in Greenland marine animals. Sci Total Environ 2000; 245: 15-24.

5. Neumann RM, Ward SM. Bioaccumulation and biomagnification of mercury in two warm water fish communities. J Freshwater Ecol 1999; 14: 487-497.

6. Clarkson TW. The toxicology of mercury. Critical reviews in clinical laboratory sciences 1997; 34: 369-403.

7. Rice D, Barone Jr S. Critical periods of vulnerability for the developing nervous system: evidence from humans and animal models. Environ Health Perspect 2000; 108: 511 .

8. Food and Agriculture Organization of the United Nations 2016 http://www.fao.org/3/a-i5555e.pdf accessed 08/12/2016

9. Ruxton CHS, Calder PC, Reed SC, Simpson MJA. The impact of long-chain n-3 polyunsaturated fatty acids on human health. Nutrition Research Reviews 2005; 18: 113-129. 
10. Gardner RM, Nyland JF, Evans SL, Wang SB, Doyle KM, Crainiceanu CM, et al. Mercury Induces an Unopposed Inflammatory Response in Human Peripheral Blood Mononuclear Cells in Vitro Environ Health Perspect 2009; 117: 1932-1938.

11. Ilback NG, Wesslen L, Fohlman J, Friman G. Effects of methyl mercury on cytokines, inflammation and virus clearance in a common infection (coxsackie B3 myocarditis) Toxicol Lett 1996; 89: 19-28.

12. Hultman P, Hansson-Georgiadis H. Methyl mercury-induced autoimmunity in mice. Toxicol Appl Pharmacol 1999; 154: 203-11.

13. Haggqvist B, Havarinasab S, Bjorn E, Hultman P. The immunosuppressive effect of methylmercury does not preclude development of autoimmunity in genetically susceptible mice. Toxicology 2005; 208: 149-164.

14. Havarinasab S, Bjorn E, Nielsen JB, Hultman P. Mercury species in lymphoid and non-lymphoid tissues after exposure to methyl mercury: correlation with autoimmune parameters during and after treatment in susceptible mice. Toxicol Appl Pharmacol 2007; 221: 21-28.

15. Crowe W, Allsopp PJ, Watson GE, Magee PJ, Strain JJ, Armstrong DJ, et al. Mercury as an environmental stimulus in the development of autoimmunity-A systematic review. Autoimmunity Reviews 2017; 16: 72-80.

16. Somers EC, Ganser MA, Warren JS, Basu N, Wang L, Zick SM, et al. Mercury exposure and antinuclear antibodies among females of reproductive age in the United States: NHANES. Environ Health Perspect 2015; 123: 792.

17. Nyland JF, Fillion M, Barbosa F, Jr, Shirley DL, Chine C, Lemire M, et al. 2011. Biomarkers of methyl mercury exposure immunotoxicity among fish consumers in Amazonian Brazil. Environ Health Perspect 119: 1733-1738. 
18. Wall R, Ross RP, Fitzgerald GF, Stanton C. Fatty acids from fish: the antiinflammatory potential of long-chain omega-3 fatty acids. Nutrition reviews 2010; 68: 280-289.

19. De Caterina R, Cybulsky MI, Clinton SK, Gimbrone MA, Libby P. The omega-3 fatty acid docosahexaenoate reduces cytokine-induced expression of proatherogenic and proinflammatory proteins in human endothelial cells. Arterioscler Thromb 1994; 14: $1829-1836$.

20. Khalfoun B, Thibault F, Watier H, Bardos P, Lebranchu Y. Docosahexaenoic and eicosapentaenoic acids inhibit in vitro human endothelial cell production of interleukin-6. Advances in experimental medicine and biology 1996; 400: 589-597.

21. Lo J, Chiu KC, Fu M, Lo R, Helton S. Fish oil decreases macrophage tumor necrosis factor gene transcription by altering the NF kappa B activity. J Surg Res $1999 ; \mathbf{8 2}$ : $216-221$.

22. Babcock TA, Novak T, Ong E, Jho DH, Helton WS, Espat NJ. Modulation of lipopolysaccharide-stimulated macrophage tumor necrosis factor- $\alpha$ production by $\omega-3$ fatty acid is associated with differential cyclooxygenase- 2 protein expression and is independent of interleukin-10. Journal of Surgical Research 2002; 107: 135-139.

23. Novak TE, Babcock TA, Jho DH, Helton WS, Espat NJ. NF-k kappa B inhibition by omega-3 fatty acids modulates LPS-stimulated macrophage TNF-alpha transcription. Am J Physiol 2003; 284: 84-89.

24. Zhao Y, Joshi-Barve S, Barve S, Chen LH, Barve S, Chen LH. Eicosapentaenoic acid prevents LPS-induced TNF-alpha expression by preventing NF-kappaB activation. J Am Coll Nutr 2004; 23: 71-78. 
25. Wallace FA, Miles EA, and Calder PC. Activation state alters the effect of dietary fatty acids on pro-inflammatory mediator production by murine macrophages. Cytokine 2000; 12: 1374-1379.

26. Bhattacharya A, Sun D, Rahman M, Fernandes G. Different ratios of eicosapentaenoic and docosahexaenoic omega-3 fatty acids in commercial fish oils differentially alter pro-inflammatory cytokines in peritoneal macrophages from C57BL/6 female mice. The Journal of nutritional biochemistry 2007; 18: 23-30.

27. Leslie CA, Gonnerman WA, Ullman MD, Hayes KC, Franzblau C, Cathcart ES. Dietary fish oil modulates macrophage fatty acids and decreases arthritis susceptibility in mice. J Exp Med 1985; 162: 1336-49.

28. Venkatraman JT, Chu WC. Effects of dietary $\omega-3$ and $\omega-6$ lipids and vitamin E on serum cytokines, lipid mediators and anti-DNA antibodies in a mouse model for rheumatoid arthritis. Journal of the American College of Nutrition 1999; 18: 602.

29. Unoda K, Doi Y, Nakajima H, Yamane K, Hosokawa T, Ishida S, et al. Eicosapentaenoic acid (EPA) induces peroxisome proliferator-activated receptors and ameliorates experimental autoimmune encephalomyelitis. Journal of neuroimmunology 2013; 56: 7-12.

30. Bates MA, Brandenberger C, Langohr II, Kumagai K, Lock AL, Harkema JR, et al. Silica-Triggered Autoimmunity in Lupus-Prone Mice Blocked by Docosahexaenoic Acid Consumption. PLoS ONE 2016; 11:

31. Espersen GT, Lervang HH, Nielsen GL, Thomsen BS, Faarvang KL, Dyerberg J. et al. Decreased interleukin-1 beta levels in plasma from rheumatoid arthritis patients after dietary supplementation with n-3 polyunsaturated fatty acids. Clinical rheumatology 1992; 11: 393-395. 
32. Kremer JM, Jubiz W, Michalek A, Rynes RI, Bartholomew LE, Bigouette J, Timchalk M, Beller D, Lininger L. Fish-oil supplementation in active rheumatoid arthritis. Ann Intern Med 1987; 106: 497-503.

33. Fortin PR, Lew RA, Liang MH, Wright EA, Beckett LA, Chalmers TC, et al. Validation of a meta-analysis: the effects of fish oil in rheumatoid arthritis. J Clin Epidemiol 1995; 48: 1379-90.

34. Adam O, Beringer C, Kless T, Lemmen C, Adam A, Wiseman M, et al. Antiinflammatory effects of a low arachidonic acid diet and fish oil in patients with rheumatoid arthritis. Rheumatol Int 2003; 23: 27-36.

35. Duffy EM, Meenagh GK, McMillan SA, Strain JJ, Hannigan BM, Bell AL. The clinical effect of dietary supplementation with omega-3 fish oils and/or copper in systemic lupus erythematosus. J Rheumatol 2004; 31: 1551-1556.

36. Wright S, O’Prey FM, McHenry MT, Leahey WJ, Devine AB, McVeigh GE, et al. A randomised interventional trial of omega-3-polyunsaturated fatty acids on endothelial function and disease activity in systemic lupus erythematosus. Ann Rheum Dis 2008; 67: $841-8$.

37. Tan EM, Cohen AS, Fries JF, Masi AT, McShane DJ, Rothfeld NF, et al. The 1982 revised criteria for the classification of systemic lupus erythematosus. Arthritis Rheumatol 1982; 25: 1271-1277.

38. Crowe W, Doherty L, Watson G, Armstrong D, Ball E, Magee P. et al. Mercury in Hair Is Inversely Related to Disease Associated Damage in Systemic Lupus Erythematosus. Int J Environ Res Public Health 2016; 13:

39. Gardner RM, Nyland JF, Silbergeld EK. Differential immunotoxic effects of inorganic and organic mercury species in vitro. Toxicology letters 2010; 198: 182190. 
40. Loveland BE, Johns TG, Mackay IR, Vailland F, Wang ZX, Hertzog PJ. Validation of the MTT dye assay for enumeration of cells in proliferative and antiproliferative assays. Biochem Int 1992; 27: 501-510.

41. Herrera-Esparza R, Barbosa-Cisneros O, Villalobos-Hurtado R, Avalos-Díaz E. Renal expression of IL-6 and TNFalpha genes in lupus nephritis. Lupus 1998; 7: 154-8.

42. Aringer M, Feierl E, Steiner G, Stummvoll GH, Höfler E, Steiner CW, et al. Increased bioactive TNF in human systemic lupus erythematosus: associations with cell death. Lupus 2002; 11: 102-108.

43. Aringer M, Graninger WB, Steiner G, Smolen JS. Safety and efficacy of TNFa blockade in systemic lupus erythematosus - an open label study. Arthritis Rheum 2004; 50: 3161-3169.

44. Matsumura R, Umemiya K, Sugiyama T, Sueishi M, Umibe T, Ichikawa K. et al. Study Group on Nephrology at the National Hospital Organization of Japan, Antitumor necrosis factor therapy in patients with difficult-to-treat lupus nephritis: a prospective series of nine patients. Clinical \& Experimental Rheumatology 2009; 27: 416.

45. Oken E, Wright RO, Kleinman KP, Bellinger D, Amarasiriwardena CJ, Hu H, et al. Maternal fish consumption, hair mercury, and infant cognition in a U.S. Cohort. Environ Health Perspect 2005; 113: 1376-80.

46. Hibbeln JR, Davis JM, Steer C, Emmett P, Rogers I, Williams C. et al. Maternal seafood consumption in pregnancy and neurodevelopmental outcomes in childhood (ALSPAC study): an observational cohort study. The Lancet 2007; 369: 578-585.

47. Strain JJ, Davidson PW, Thurston SW, Harrington D, Mulhern MS, McAfee AJ, et al. Maternal PUFA status but not prenatal methylmercury exposure is associated with 
children's language functions at age five years in the Seychelles. J Nutr 2012; 142: 1943-9.

48. Choi AL, Mogensen UB, Bjerve KS, Debes F, Weihe P, Grandjean P, et al. Negative confounding by essential fatty acids in methylmercury neurotoxicity associations. Neurotoxicology and teratology 2014; 42: 85-92.

49. Kaplan MJ. Neutrophils in the pathogenesis and manifestations of SLE. Nature Reviews Rheumatology 2011; 7: 691-699.

50. Shimoda N, Fukazawa N, Nonomura K, Fairchild RL. Cathepsin g is required for sustained inflammation and tissue injury after reperfusion of ischemic kidneys. The American journal of pathology 2007; 170: 930-940.

51. Wu CC, Chen JS, Wu WM, Liao TN, Chu P, Lin SH, et al. Myeloperoxidase serves as a marker of oxidative stress during single haemodialysis session using two different biocompatible dialysis membranes. Nephrology Dialysis Transplantation 2005; 20: 1134-1139.

52. Wada T, Yokoyama H, Tomosugi N, Hisada Y, Ohta S, Naito T, et al. Detection of urinary interleukin-8 in glomerular diseases. Kidney international 1994; 46: 455-460.

53. Grammer AC, Lipsky PE. B cell abnormalities in systemic lupus erythematosus. Arthritis Res Ther 2003; 5: 1.

54. Linker-Israeli M, Deans RJ, Wallace DJ, Prehn J, Ozeri-Chen T, Klinenberg JR. Elevated levels of endogenous IL-6 in systemic lupus erythematosus: a putative role in pathogenesis. J. Immunol 1991; 147: 117-123.

55. Calder PC. Polyunsaturated fatty acids and inflammatory processes: new twists in an old tale. Biochimie 2009; 91: 791-795.

56. Calder PC. $n-3$ polyunsaturated fatty acids, inflammation, and inflammatory diseases. AJCN 2006; 83: 1505-1519. 
57. Hoesel B, Schmid JA. The complexity of NF- $\kappa$ B signaling in inflammation and cancer. Molecular cancer 2013; 12: 1.

58. Sun Q, Ma J, Campos H, Rexrode KM, Albert CM, Mozaffarian D, et al. Blood concentrations of individual long-chain $n-3$ fatty acids and risk of nonfatal myocardial infarction. Am J Clin Nutr 2008; 88: 216-223.

59. Silva JCD, Mariz HA, Júnior R, Oliveira PSSD, Dantas AT, Duarte ALBP, et al. Hydroxychloroquine decreases Th17-related cytokines in systemic lupus erythematosus and rheumatoid arthritis patients. Clinics 2013; 68: 766-771.

60. Kremer JM, Lawrence DA, Hamilton R, McInnes IB. Long-term study of the impact of methotrexate on serum cytokines and lymphocyte subsets in patients with active rheumatoid arthritis: correlation with pharmacokinetic measures. RMD Open 2016; 2:

61. Heggland I, Kaur P, Syversen T. Uptake and efflux of methylmercury in vitro: Comparison of transport mechanisms in C6, B35 and RBE4 cells. Toxicology In Vitro 2009; 23: 1020-1027. 
Table 1: Mean (SD) cytokine concentrations from PBMCs of SLE patients $(\mathrm{N}=12)$ and healthy controls $(\mathrm{N}=12)$ following $\mathrm{MeHg} \&$ LPS or LPS exposure alone

\begin{tabular}{|c|c|c|c|c|c|}
\hline \multirow[b]{2}{*}{ Cytokine } & \multicolumn{2}{|c|}{ SLE } & \multicolumn{2}{|c|}{ Healthy } & \multirow[b]{2}{*}{$\mathrm{P}=$} \\
\hline & LPS & LPS \& MeHg & LPS & LPS \& MeHg & \\
\hline IL-1 $\beta$ & $92.39(79.65)$ & $167.13(98.07)$ & $37.07(38.12)$ & $65.68(68.09)$ & 0.487 \\
\hline IL-2 & $59.62(93.33)$ & $84.99(69.98)$ & $34.97(29.88)$ & $46.26(59.42)$ & 0.554 \\
\hline IL-4 & $2.84(6.91)$ & $19.27(45.63)$ & $0.69(1.40)$ & $4.77(3.32)$ & 0.424 \\
\hline IL-6 & $1892.28(3229.30)$ & $3498.54(7008.70)$ & $510.46(657.54)$ & $861.45(814.58)$ & 0.597 \\
\hline IL-8 & $25209.33(22986.28)$ & $27587.60(26469.74)$ & $14419.11(22084.62)$ & $15316.33(16876.38)$ & 0.688 \\
\hline IL-10 & $152.23(111.59)$ & $93.30(125.32)$ & $180.71(125.11)$ & $96.63(123.96)$ & 0.933 \\
\hline IL-12p70 & $13.42(11.60)$ & $23.69(53.88)$ & $187.45(9.43)$ & $172.21(25.22)$ & 0.315 \\
\hline IL-13 & $219.58(138.28)$ & $190.92(110.81)$ & $187.45(107.21)$ & $172.21(236.43)$ & 0.992 \\
\hline TNF- $\alpha$ & $979.30(1656.39)$ & 2226.01 (348.98) & $390.93(2752.68)$ & $701.40(680.65)$ & $0.008 *$ \\
\hline
\end{tabular}

Analysis was conducted using ANCOVA, comparing cytokine concentrations of SLE patients with healthy controls following $\mathrm{MeHg}$ and LPS with cytokine concentrations from cells exposed to LPS alone as a covariate. Cytokine concentrations expressed in $\mathrm{pg} / \mathrm{mL}$. P values below 0.05 are considered significant.

LPS: lipopolysaccharide, MeHg: methylmercury, SD: standard deviation, SLE: systemic lupus erythematosus, PBMC: peripheral blood mononuclear cells 
Table 2: Mean (SD) cytokine concentrations from PBMCs of SLE patients $(\mathrm{N}=12)$ and healthy controls $(\mathrm{N}=12)$ following $\mathrm{MeHg} \&$ LPS and EPA, MeHg \& LPS exposure

SLE

Healthy

\begin{tabular}{cccccccc}
\cline { 2 - 3 } Cytokine & MeHg \& LPS & EPA, MeHg \& LPS & & MeHg \& LPS & EPA, MeHg \& LPS & P = \\
\hline IL-1 $\beta$ & $167.13(98.07)$ & $28.8(45.41)$ & & $65.68(68.09)$ & $2.97(2.71)$ & 0.270 \\
IL-2 & $84.99(69.98)$ & $23.09(51.23)$ & & $46.26(59.42)$ & $4.4(3.60)$ & 0.187 \\
IL-4 & $19.27(45.63)$ & $2.42(3.66)$ & & $4.77(3.32)$ & $0.08(0.095)$ & 0.062 \\
IL-6 & $3498.54(7008.70)$ & $379.64(617.78)$ & & $861.45(814.58)$ & $20.11(24.02)$ & 0.152 \\
IL-8 & $27587.60(26469.74)$ & $\mathbf{2 1 3 7 . 8 3 ( 1 5 5 9 . 0 1 )}$ & & $15316.33(16876.38)$ & $\mathbf{8 7 9 . 2 6 ( 9 7 9 . 4 9 )}$ & $\mathbf{0 . 0 3 0}$ \\
IL-10 & $93.30(125.32)$ & $69.59(189.23)$ & & $96.63(123.96)$ & $4.15(4.95)$ & 0.242 \\
IL-12p70 & $23.69(53.88)$ & $0.89(2.46)$ & & $172.21(25.22)$ & $0.13(0.41)$ & 0.513 \\
IL-13 & $190.92(110.81)$ & $82.18(104.96)$ & & $172.21(236.43)$ & $22.9(25.30)$ & 0.076 \\
TNF- $\alpha$ & $2226.01(348.98)$ & $234.42(312.03)$ & & $701.40(680.65)$ & $37.96(44.36)$ & 0.132 \\
\hline
\end{tabular}

Analysis was conducted using ANCOVA, comparing cytokine concentrations of SLE patients with healthy controls following exposure to $\mathrm{MeHg}$, LPS and EPA with cytokine concentrations from cells exposed to MeHg \& LPS alone as a covariate.

Cytokine concentrations expressed in $\mathrm{pg} / \mathrm{mL}$. P values below 0.05 are considered significant

EPA: eicosapentaenoic acid, LPS: lipopolysaccharide, MeHg: methylmercury, SD: standard deviation, SLE: systemic lupus erythematosus, PBMC: peripheral blood mononuclear cells 
Table 3: Mean (SD) cytokine concentrations from PBMCs of SLE patients $(\mathrm{N}=12)$ and healthy controls $(\mathrm{N}=12)$ following MeHg \& LPS and DHA, MeHg \& LPS exposure

\begin{tabular}{ccccccc} 
& \multicolumn{2}{c}{ SLE } & & \multicolumn{2}{c}{ Healthy } \\
\cline { 2 - 3 } Cytokine & MeHg \& LPS & DHA, MeHg \& LPS & & MeHg \& LPS & DHA, MeHg \& LPS & P = \\
\hline IL-1 $\beta$ & $167.13(98.07)$ & $24.11(48.99)$ & & $65.68(68.09)$ & $2.89(2.24)$ & 0.257 \\
IL-2 & $84.99(69.98)$ & $3.71(4.84)$ & & $46.26(59.42)$ & $7.6(12.80)$ & 0.254 \\
IL-4 & $19.27(45.63)$ & $1.6(2.93)$ & & $4.77(3.32)$ & $0.07(0.16)$ & 0.185 \\
IL-6 & $3498.54(7008.70)$ & $683.25(1961.84)$ & & $861.45(814.58)$ & $23.32(29.59)$ & 0.159 \\
IL-8 & $27587.60(26469.74)$ & $2962.86(4213.09)$ & & $15316.33(16876.38)$ & $1121.18(1099.89)$ & 0.165 \\
IL-10 & $93.30(125.32)$ & $26.45(60.10)$ & & $96.63(123.96)$ & $9.96(10.87)$ & 0.355 \\
IL-12p70 & $23.69(53.88)$ & $4.01(8.50)$ & & $172.21(25.22)$ & $0.13(0.17)$ & 0.154 \\
IL-13 & $190.92(110.81)$ & $67.88(91.15)$ & & $172.21(236.43)$ & $9.94(11.45)$ & 0.517 \\
TNF- $\alpha$ & $2226.01(348.98)$ & $515.07(1276.77)$ & & $701.40(680.65)$ & $65.84(55.88)$ & 0.516 \\
\hline
\end{tabular}

Analysis was conducted using ANCOVA, comparing cytokine concentrations of SLE patients with healthy controls following MeHg, LPS and DHA with cytokine concentrations from cells exposed to MeHg \& LPS alone as a covariate. Cytokine concentrations expressed in $\mathrm{pg} / \mathrm{mL}$.

DHA: docosahexaenoic acid, LPS: lipopolysaccharide, MeHg: methylmercury, SD: standard deviation, SLE: systemic lupus erythematosus, PBMC: peripheral blood mononuclear cells 
Figure 1: Flow diagram of experimental protocol.

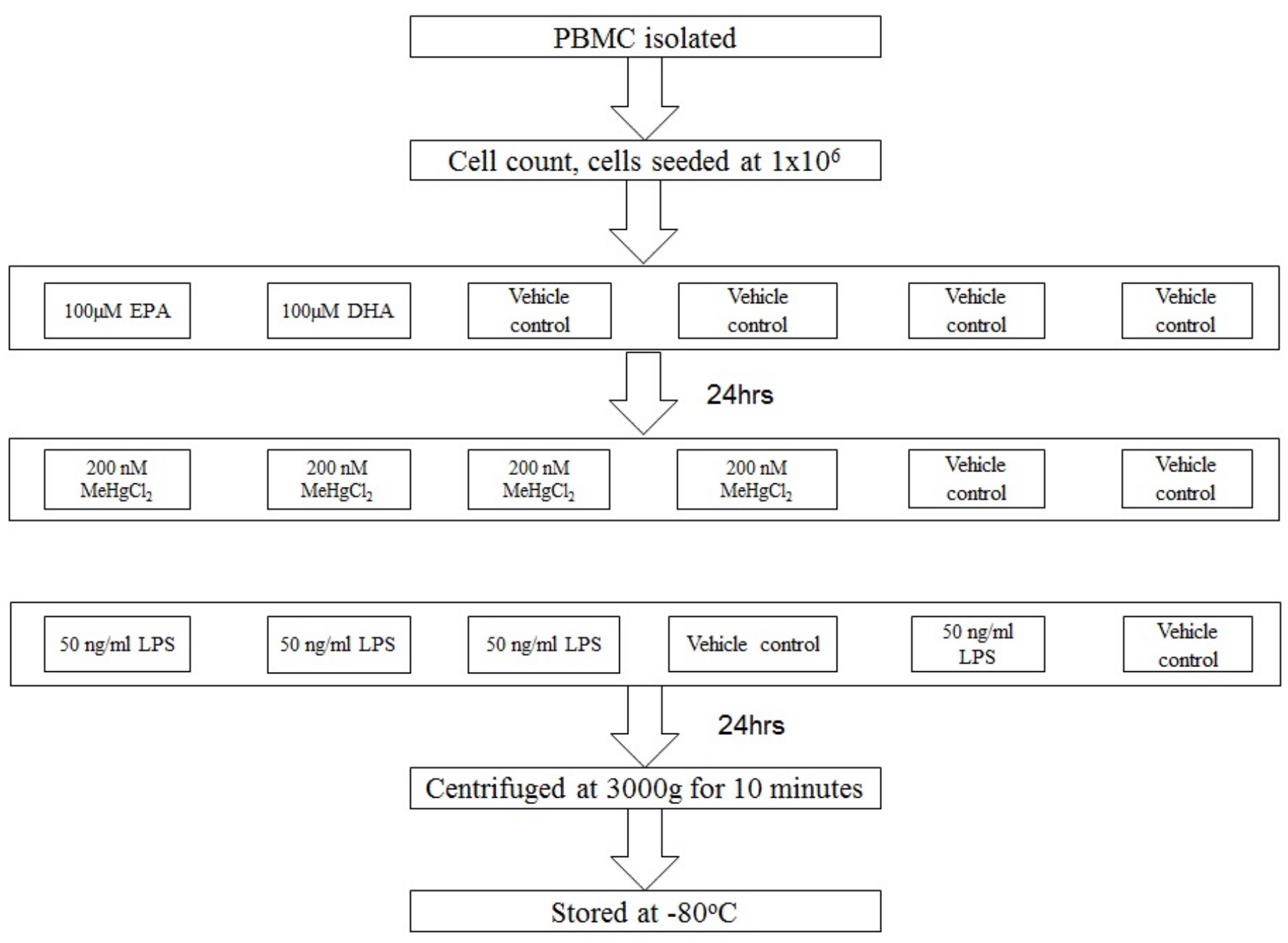

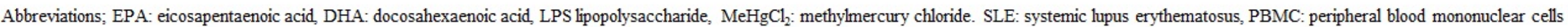

